\title{
Celiac Disease and Osteoporosis: A Review
}

\author{
José-Luis Pérez-Castrillón ${ }^{*}{ }^{, 1,4}$, Maria Andres-Calvo ${ }^{1}$, Elena Izquierdo-Delgado ${ }^{1}$, \\ Marcelino Mendo ${ }^{3}$, Daniel de Luis ${ }^{2,4}$ and Antonio Dueñas-Laita ${ }^{1}$ \\ ${ }^{I}$ Department of Medicine, University Hospital Rio Hortega, University of Valladolid, Spain \\ ${ }^{2}$ Research Unit, University Hospital Rio Hortega, University of Valladolid, Spain \\ ${ }^{3}$ Department of Radiology, University Hospital Rio Hortega, University of Valladolid, Spain \\ ${ }^{4}$ RETICEF (Thematic Network of Cooperative Research into Aging and Fragility)
}

\begin{abstract}
Celiac disease is a highly-prevalent autoimmune disease characterized by chronic intestinal inflammation. Osteoporosis may be a complication of celiac disease in both the classic presentation where digestive symptoms predominate and in subclinical forms where it may be the initial manifestation of the disease. Various etiopathogenic mechanisms have been reported in osteoporosis which may explain its appearance in celiac disease. There are no studies of sufficient quality evaluating the prevalence of osteoporosis in celiac disease in accordance with World Health Organization densitometric criteria. Although an increased risk of osteoporotic fracture has been reported, bone mineral density testing in patients with celiac disease is not cost-effective. A gluten-free diet increases bone mass to nearly-normal levels and specific treatment for patients with a high risk of osteoporotic fracture is required. There are no studies analyzing the efficacy of anabolic and anti-catabolic drugs in patients with celiac disease.
\end{abstract}

Keywords: Celiac disease, osteoporosis, bone mineral density, fracture.

\section{INTRODUCTION}

Celiac disease is a highly-prevalent (1\%) autoimmune disease characterized by chronic intestinal inflammation with different degrees of intestinal atrophy that may be associated with malabsorption. The mechanism of production is immunologic and is due to intolerance to gluten, a protein found in some grains, in genetically-predisposed people. This immune response promotes an inflammatory reaction that is mediated by the innate and adaptive immune systems, with the secretion of inflammatory cytokines. In the classic presentation of the disease, there is a predominance of digestive symptoms with a clinical profile of malabsorption syndrome [1]. However, on many occasions, celiac disease presents subclinically, with a predominance of extraintestinal manifestations. Iron-deficiency anemia is the most common presentation in $27 \%$ of cases, followed by Graves' disease in $25 \%$, and insulin-dependent diabetes in $20 \%$ of cases. Osteoporosis appears in $6.81 \%$ of the forms that debut with extraintestinal manifestations although it may be a complication of the most severe forms as a result of a reduction in the intestinal absorption of calcium and vitamin $\mathrm{D}[2]$.

Celiac disease appears at an early age, when the prevalence of osteoporosis is low but, in the long term, people with celiac disease have a higher incidence of osteoporotic fracture than the general population. Therefore,

*Address correspondence to this author at the Hospital Río Hortega, Rondilla Santa Teresa 9, 47010 Valladolid, Spain; Tel: (+34) 983-420400; Fax: (+34) 983-331566; E- mail: castrv@terra.es determining the mechanisms that condition the reduction in the quality and amount of bone and the establishment of preventive measures in patients with celiac disease is necessary. The purpose of this paper is a review of celiac disease and associated osteoporosis

\section{ETIOPATHOGENESIS}

Osteoporosis results from alterations in bone remodeling that cause an imbalance between bone formation and resorption, with a predominance of resorption resulting in a reduction in bone strength and the appearance of fractures. Bone remodeling is a physiological process whose function is the permanent renovation of the skeleton in order to ensure biomechanically-correct bone function [3]. It consists of an initial phase of bone resorption followed by a phase of formation, both of which are regulated by general (endocrine) factors and local (paracrine) factors. The main endocrine factors include calciotropic hormones (parathyroid hormone $[\mathrm{PTH}]$ and vitamin $\mathrm{D}$ ) and sexual hormones, mainly estrogens and, to a lesser extent, androgens. Other hormones, including the thyroid hormones, growth hormone and leptin play a smaller role. Local factors include various cytokines and growth factors that regulate the process, with the inflammatory cytokines IL-1, IL- 6 and TNF- $\alpha$ playing a role key [4]. This process has a final common pathway, the RANK/RANKL/OPG (Receptor Nuclear Activator Factor Kappa B/Receptor Nuclear Activator Factor Kappa B Ligand/Osteoprotegerin) system, which intervenes in the regulation of remodeling.

Estrogens and the PTH-vitamin D system are the most important hormonal systems involved in the regulation of 
bone remodeling. Estrogens exert a beneficial effect on both bone and circulatory tissue. The reduction in estrogen levels during the menopause activates the RANKL system, increasing the number and activity of osteoclasts and facilitating bone resorption. In addition, it activates the secretion of IL-7, which acts on T-lymphocytes, liberating mediators (TNF $\alpha$ and IL-6) that increase bone resorption, either by acting directly on osteoclasts or by activating the RANKL system [5].

Vitamin D, previously considered an "anti-rickets" factor, and later as a vitamin, is now identified as an endocrine system with a key role in the regulation of the phospho-calcium metabolism. Vitamin D comes from two main sources: the diet and cutaneous synthesis of ultraviolet radiation. Once it reaches the bloodstream, it bonds with DBP, a transport protein, and is activated by various metabolic processes. In the liver, it undergoes hydroxylation at the 25 carbon, giving rise to $25-$ hydroxycholecalciferol [6], a metabolite which is the main indicator of vitamin D levels in the body, due to its long half-life and because its concentration is directly related to the level of substrate without undergoing enzymatic regulation. Later, a second hydroxylation occurs in the kidney, in carbon 1, giving rise to 1,25-dihydroxy-cholecalciferol, the active metabolite. Its effect is exerted by bonding with the receptor of vitamin D, causing a conformational change in the receptor and its bonding with the receptor $\mathrm{X}$ of retinoic acid to form a heterodimer, VDR-RXR. This structure penetrates the nucleus and inhibits or stimulates various genes. Vitamin D, besides increasing intestinal calcium absorption also reduces levels of PTH, improving the amount and quality of bone [7].

The main regulator and final pathway of bone remodeling is the RANK/RANKL/OPG system. During bone remodeling, bone marrow cells and osteoblasts produce RANKL, which bonds with a transmembrane receptor of the osteoclast precursor, RANK, causing their differentiation and activation. In addition, it induces an inflammatory response mediated by IL-6. Osteoprotegerin (OPG) is a glycoprotein that acts as a decoy receptor of RANKL, impeding the activation of osteoclastogenesis [8].

The link between celiac disease and the etiopathogenic schema of osteoporosis may differ according to whether the presentation is classic or subclinical. In the classic, severe forms, with evident malabsorption, there is a reduction in plasma calcium and vitamin D levels. Due to atrophy of the villi there is a reduction in the active absorption surface, giving rise to steatorrhea, which has a chelating effect on calcium and vitamin $\mathrm{D}$, making their absorption difficult. This is associated with a reduction in the levels of the vitamin D transporting protein (calbindin and calciumbinding protein). These deficits increase PTH concentrations which, in turn, lead to increased bone remodeling resulting in reduced bone mass and an alteration of bone quality, with the consequent reduction in bone strength and a greater risk of fractures [9]. Other endocrine factors that may contribute to this process are a reduction in IGF-1 related to the malabsorption of zinc and reduced levels of leptin [10], which have been correlated with anthropometric data but not with bone mass.
The mild, asymptomatic forms may reduce bone mass by a different mechanism related to the secretion of inflammatory cytokines. The reported pattern of cytokine production consists of an increase in interferon- $\gamma$, IL- 6 , TNF$\alpha$ and IL-18 levels and reduced levels of IL-12 [11]. Interferon- $\gamma$ causes different responses in bone cells with conflicting results according to whether the analysis is in vivo or in vitro. It may stimulate or inhibit osteoclasts and, in addition, reduces the synthesis of collagen by osteoblasts. The inflammatory cytokines (IL-1, IL-6, TNF $\alpha$ ) increase bone resorption, acting directly on the osteoclasts or increasing the RANKL/OPG ratio [12]. IL-18 acts synergically with IL-12, inducing the production of interferon- $\gamma$, which reduces the number of osteoclasts and inhibits their activation by increased OPG synthesis. However, IL-12, the key cytokine in the inhibition of the osteoclastic response, is reduced in patients with celiac disease [13]. Taranta et al. [14], in a study of 32 celiac patients with reduced bone mass, found increased serum levels of IL-6, IL-18, RANKL, OPG and RANKL/OPG and a reduction in IL-12. In addition, the serum of these patients was able to stimulate osteoclasts in in vitro cultures. Similarly, Moreno et al. [15] observed an association between bone mass and a polymorphism of the IL1 $\beta$ gene (SNP IL1 $3-511)$ and concluded that the genetic factors that intervene in the regulation of the immune response may contribute to metabolic bone disease in celiac patients.

\section{OSTEOPOROSIS AND CELIAC DISEASE}

Osteoporosis is a systemic disease characterized by a reduction in bone strength that facilitates the appearance of fractures, the characteristic complication of the disease. Bone strength is determined by bone mass and bone quality [16]. Bone mass can be measured by bone densitometry but bone quality cannot be measured by any validated, clinicallyapplicable measure. The prevalence of osteoporosis in patients with celiac disease may be estimated in two ways.

The first is measurement of bone mineral density (BMD) with a central densitometer and application of the World Health Organization criteria, although it should be remembered that these criteria were developed for white postmenopausal women. Celiac disease has a high prevalence in premenopausal women and males, which makes assessment difficult. There are no studies of sufficient methodological quality that measure BMD in patients with celiac disease. There are 18 small reported studies (only one has a sample size $>100$ ) and only four with a control group. As this is a premenopausal population, the results are expressed as a Zscore (bone mass adjusted by age and sex) which makes application of the WHO criteria difficult. Analysis of these studies reveals a prevalence of spinal osteoporosis of $56 \%$ and of hip osteoporosis of $11 \%$ and a higher prevalence of osteopenia, ( $41 \%$ in the spine and $43 \%$ in the hip). The small number of patients evaluated $(<700)$ is a significant limitation [17]. In light of these data, no valid conclusion can be drawn on the prevalence of osteoporosis in celiac patients using densitometric diagnostic criteria.

The second way is determination of the prevalence of fractures, specifically low-impact fractures in sites characteristic of osteoporosis (vertebral, Colles, hip). Ten studies have been published since 2000, some of them of high 
quality and with a large number of patients, including casecontrol and cohort studies and one meta-analysis.

Of the five reported case-control studies, four show a greater risk of fractures and one does not, although this last study showed a non-significant trend to a greater risk. Vazquez et al. [18] found that $25 \%$ of celiac patients severe forms of the disease due to malabsorption syndrome had peripheral fractures compared with $8 \%$ of controls (OR 3.5; 95\% CI 1.8-7.2) and an OR for vertebral fractures of 2.18 (95\% CI 0.7-11.5. NS). Fickling [19] analyzed previous fractures in patients admitted to a digestive unit and found an increased risk of $7 \%$ in celiac patients with a higher mean age and a body mass index (BMI) within normal limits. Moreno et al. [20] studied all fractures (osteoporotic and nonosteoporotic), with an increase of $7 \%$ although the quality of the study was reduced due to the discordance between cases (14) and controls (296). A case-control study of post-menopausal women aged older 50 years included 383 celiac patients and 445 controls and found an increased risk of fractures in celiac patients (OR 1.51;95\% CI 1.13-2.02) [21]. Only Thomason et al. [22] who analyzed different types of fractures (previous fractures, all fractures, low intensity fractures and Colles fractures) in 274 celiac patients and 224 controls did not find significant differences. A nonsignificant trend to a greater risk was observed.

The largest studies of celiac disease and fractures are cohort studies, most of which were retrospective.
Vestergaard et al. [23] studied 1100 celiac patients and 23316 controls admitted to hospitals in the Copenhagen area and found no greater risk of fractures. The study was powered to show an increased risk of 1.2-1.3 but the diagnostic criteria of celiac disease were not clearly established, reducing the validity of the conclusions. West et al. [24] used the General Practice Research Database (GPRD) to study 4732 patients with celiac disease and 23620 controls. They found 356 fractures in celiac patients (24 in the hip). There was an increased risk in all three types of assessment made: fractures (OR 1.3, 95\% CI 1.16-1.46), hip fractures (OR 1.9, 95\% CI 1.2-3.02) and Colles fractures (OR 1.77, 95\% CI 1.35-2.34). However, the absolute increase in risk was only 3.19 fractures/1000 persons/ year. Ludvigsson et al. [25] used the Swedish National Register to analyze 13724 celiac patients and 65627 controls. Patients were recruited from hospital records and therefore may have had more-severe involvement. Sixty percent were aged older 15 years. All fractures and hip fractures (the most severe complication of osteoporosis in terms of morbidity and mortality) were evaluated. There was an increased risk of any type of fracture (OR 1.4, 95\% CI 1.3-3.5) and of hip fracture (OR 2.1, 95\% CI 1.8-2.4). Interestingly, introduction of a gluten-free diet did not modify the risk of fracture. This may be because celiac children are not able to reach their genetically predetermined peak of bone mass, which determines a greater facility to reach fracture thresholds when they are older.

Table 1. Occurrence of Fractures in Celiac Disease

\begin{tabular}{|c|c|c|c|c|}
\hline Author & Study & Population & Objective & OR $(95 \% \mathrm{CI})$ \\
\hline Vazquez et al. [18] & Case-Control & $\begin{array}{c}330 \\
165 \text { celiac patients and } 165 \text { controls }\end{array}$ & $\begin{array}{l}\text { Peripheral fractures } \\
\text { Spine }\end{array}$ & $\begin{array}{l}3.5(1.8-7.2) \\
2.8(0.7-11.5)\end{array}$ \\
\hline Fickling et al. [19] & Case-Control & $\begin{array}{l}150 \\
75 \text { celiac patients and } 75 \text { controls }\end{array}$ & Previous fractures & $7 \%$ \\
\hline West et al. [24] & Retrospective cohorts & $\begin{array}{c}28352 \\
1100 \text { celiac patients and } 23620 \text { controls }\end{array}$ & $\begin{array}{c}\text { Fractures } \\
\text { Hip fractures } \\
\text { Colles fractures }\end{array}$ & $\begin{array}{c}1.3(1.16-1.46) \\
1.9(1.2-3.02) \\
1.77(1.35-2.34)\end{array}$ \\
\hline Thomson et al. [22] & Case-Control & $\begin{array}{c}410 \\
244 \text { celiac patients and } 166 \text { controls }\end{array}$ & $\begin{array}{c}\text { Previous fracture } \\
\text { Fractures } \\
\text { Low intensity } \\
\text { Colles fractures }\end{array}$ & $\begin{array}{c}1.29(0.65-2.39) \\
1.21(0.66-2.25) \\
1(0.68-1.2) \\
1.16(0.65-2.39)\end{array}$ \\
\hline Moreno et al. [20] & Case-Control & $\begin{array}{c}311 \\
14 \text { celiac patients and } 296 \text { controls }\end{array}$ & Fractures & $3.6(1.7-7.5)$ \\
\hline Davie et al. [21] & Case-Control & $\begin{array}{c}812(>50 \text { years }) \\
383 \text { celiac patients and } 445 \text { controls }\end{array}$ & Fractures & $1.51(1.13-2.02)$ \\
\hline $\begin{array}{l}\text { Ludvigsson et al. } \\
{[25]}\end{array}$ & Retrospective cohort & $\begin{array}{c}78000 \\
15000 \text { celiac patients and } 65000 \text { controls }\end{array}$ & $\begin{array}{c}\text { Fractures } \\
\text { Hip }\end{array}$ & $\begin{array}{l}1.4(1.3-3.5) \\
2.1(1.8-2.4)\end{array}$ \\
\hline Jafri et al. [26] & Retrospective-prospective cohorts & $\begin{array}{c}249 \\
83 \text { celiac patients and } 166 \text { controls }\end{array}$ & $\begin{array}{l}\text { Retrospective fractures } \\
\text { Prospective fractures }\end{array}$ & $\begin{array}{c}2.0(1-3.9) \\
2.5(1.5-5.6)\end{array}$ \\
\hline Olmos et al. [27] & Meta analysis & $\begin{array}{c}117732 \\
23955 \text { celiac patients and } 96777 \text { controls }\end{array}$ & Fractures & $1.45(1.15-1.78)$ \\
\hline
\end{tabular}


A small, but homogenous study carried out in Minnesota, USA [26] found a greater prevalence of osteoporosis in celiac patients than in controls $(17 \% v s .7 \%, \mathrm{p}=0,010)$. The risk of fracture was greater both in the retrospective (OR 2.0, 95\% CI 1-3.9) and prospective (OR 2.5, 95\% CI 1.1-5.6) phases. The increased risk was observed both in axial and peripheral fractures.

A recent meta-analysis by Olmos et al. [27] included eight studies with a total of 20955 celiac patients with 1819 fractures $(8.7 \%)$ and 96777 controls with 5955 fractures (6.15\%) (OR 1.45; 95\% CI 1.15-1.71). Of the eight studies, six showed an increased risk and two did not. Celiac disease increased the risk of fracture by $43 \%$. The greatest defect of this meta-analysis is its statistical heterogeneity, which the authors tried to solve in two ways. Studies showing a positive association but with low statistical precision were excluded: the risk remained increased by $27 \%$. Secondly, the population was subdivided into patients recruited from hospitals and those included in cohorts studies, based on the different risk. The risk was increased in both populations.

Table 1 shows the studies included. Overall, they show that patients with celiac disease present a greater risk of osteoporotic fracture.

\section{DENSITOMETRY AND CELIAC DISEASE}

The above-mentioned studies, which show a greater risk of osteoporotic fracture in people with celiac disease, suggest the requirement for bone mass screening in all celiac patients. However, considering the high prevalence of celiac disease $(1 \%)$ and the modestly-increased risk of fracture, densitometric studies of all celiac patients, as in menopausal women, are not cost-effective. It seems reasonable to carry out densitometric studies only in sub-groups at high-risk of fracture. There are no evidence-based studies that analyze these issues and, therefore, expert opinion is the best guide at present. An editorial [28] by Compstom suggests carrying out densitometry in the following groups: non-compliant patients or those in whom a gluten-free diet has failed, patients treated with corticosteroids, hypogonadism, age older 70 years, BMI lower 20 and previous fragility fractures. However, as celiac disease may be silent, with osteoporosis as the first manifestation, some authors suggest the need for celiac screening in all osteoporotic patients, or at least those who fail treatment [29].

\section{TREATMENT}

The first therapeutic measure in patients with celiac disease is a gluten-free diet, which, although it does not exclude a greater risk of fracture, increases BMD. Valdimarsson et al. [30] carried out a case-control study of 63 celiac patients on a gluten-free diet and 252 controls followed for one year. They found an increase in bone mass in all sites and in all clinical presentations of the disease. Mataulen et al. [31] carried out a similar study and found increases of $5 \%$ in the lumbar spine and $5 \%$ in the hip, results similar to those achieved by bisphosphonates in the treatment of postmeno-pausal osteoporosis, with a reduction in bone remodeling. Administration of calcium and vitamin D did not provide additional benefits. This effect was achieved through the suppression of PTH, which is responsible for increased bone turnover. Kemppainen et al. [32] analyzed 28 recently-diagnosed celiac patients (9 men and 19 women) following a gluten-free diet for five years. There was an increase in BMD in both men and women, especially during the first year, which was maintained during the four following years. Normal levels of PTH and vitamin D were observed at the end of the follow-up. Sategna-Guidetti et al. [33] analyzed 86 celiac patients, of whom $40 \%$ were osteopenic and $26 \%$ osteoporotic and found an increase in bone remodeling and PTH and a reduction in vitamin D. Introduction of a gluten-free diet resulted in an increase in BMD in $83.7 \%$ of patients, with an improvement in biochemical parameters.

The specific indications for treatment for osteoporosis in patients with celiac disease are fragility fracture and low BMD with an increased risk of fracture [17]. The drugs used are the same as those of postmenopausal osteoporosis, with bisphosphonates being the gold standard [34]. However, there are no systematic data on the efficacy of bisphosphonates or other drugs in the treatment of osteoporosis in patients with celiac disease. Zoledronate IV given as a yearly dose may be a useful therapeutic option in these patients, as the Horizon study [35] has shown its efficacy in reducing vertebral, nonvertebral and hip fractures, while parenteral administration would avoid absorption problems.

\section{REFERENCES}

[1] Green PHR, Cellier C. Celiac disease. N Engl J Med 2007; 257: 1731-43.

[2] Karakan T, Ozyemisci-Takisran O, Gunendi Z, Atalay F, Tuncer C. Prevalence of IgA-antiendomisial antibody in a patient cohort with idiopathic low bone mineral density. Wordl J Gastroenterol 2007; 13: 2788-92

[3] Perez-Castrillón JL, De Luis D, Dueñas-Laita A. Atherosclerosis and osteoporosis. Minerva Med 2008; 99: 45-54.

[4] Gonzalez-Macias J, Olmos Martinez JM. Fisiopatología de la osteoporosis. Medicine 2006; 9:1-7.

[5] Zaidi M. Skeletal remodelling in health and disease. Nat Med 2007; 13: 792-801.

[6] Holick MF. Sunlight and vitamin D for bone health and prevention of autoinmune diseases, cancer and cardiovascular disease. Am J Clin Nutr 2004; 80: 1678-88.

[7] Holick MF. Vitamin D deficiency. N Engl J Med 2007; 357: 26681.

[8] Khosla S. Minireview: the OPG/RANK/RANKL system. Endocrinology 2001; 142: 5050-5.

[9] Bianchi ML, Bardella MT. Bone in celiac disease. Osteoporis Int 2008; 19(12): 1705-16.

[10] Jameson S. Coeliac disease, insulin-like growth factor, bone mineral density and zinc. Scand J Gastroenterol 2000; 35: 894-6.

[11] Bardella MT, Bianchi ML, Teti A. Chronic inflammatory intestinal disease and bone loss. Gut 2005; 54: 1508.

[12] McCormick MN, Pacifici R. The role of T lymphocytes in bone metabolism. Immunol Rev 2005; 208: 154-68.

[13] Shanmugarajan S, Kawanabe N, Koide M, Arroyo JE, Key LL, Reddy SV. IL-12 stimulates the osteoclast inhibitory peptide-1 (OIP-1) gene expression in CD4+ T-cells. J Bone Miner Res 2008 ; 23 (Suppl 1): S168.

[14] Taranta A, Fortunati D, Longo $\mathrm{M}$, et al. Imbalance of osteoclastogenesis-regulating factors in patients with celiac disease. J Bone Miner Res 2004; 19: 1112-21.

[15] Moreno ML, Crusius JBA, Cherñavsky A, et al. The IL-1 gene family and bone involvement in celiac disease. Immunogenetics 2005; 57: 618-20.

[16] Raizs LG. Pathogenesis of osteoporosis: concepts, conflicts and prospects. J Clin Invest 2005; 115: 3318-25.

[17] Lewis NR, Scott BB. Guidelines for osteoporosis in inflammatory bowel disease and celiac disease. BSG Guidelines in Gastroenteroly. June 2007. Available from: www. bsg.org.uk 
[18] Vazquez H, Mazure R, Gonzalez D, et al. Risk of fracture in celiac disease patients: a cross-sectional, case-control study. Am J Gastroenterol 2000; 95: 183-9.

[19] Fickling WE, McFarlane XA, Bhalla AK, et al. The clinical impact of metabolic bone disease in celiac disease. Postgrad Med J 2001; 77: 33-6.

[20] Moreno ML, Vazquez H, Mazure R, et al. Stratification of bone fracture risk in patients with celiac disease. Clin Gastroenterol Hepatol 2004; 2: 127-34.

[21] Davie MW, Gaywood I, George E, et al. Excess non-spine fractures in women over 50 years with celiac disease: a crosssectional, questionnaire-based study. Osteoporos Int 2005; 16: $1150-5$.

[22] Thomason K, West J, Logan RFA, et al. Fracture experience of patients with celiac disease: a population based survey. Gut 2003; 52: 518-22.

[23] Vestergaard P, Mosekilde L. Fracture risk in patients with celiac disease, Crohn's disease and ulcerative colitis: a nationwide follow-up study of 16416 patients in Denmark. Am J Epidemiol 2002; 156: 1-10.

[24] West J, Logan RFA, Card TR, Smith C, Hubbard R. Fracture risk in people with celiac disease: a population-based cohort study. Gastroenterology 2003; 125: 429-36.

[25] Ludvigsson JF, Michaelsson K, Ekbom A, Montgomery SM. Coeliac disease and the risk of fractures. A general populationbased cohort study. Aliment Pharmacol Ther 2007; 25: 273-85.

[26] Jafri MR, Nordstrom CW, Murray JA, et al. . Long-term fracture risk in patients with celiac disease: a population-based study in Olmsted County, Minnesota. Dig Dis Sci 2008; 53: 964-71.
[27] Olmos M, Antelo M, Vazquez H, Smecuol E, Mauriño E, Bai JC. Systematic review and meta-analysis of observational studies on the prevalence of fractures in celiac disease. Digest Liver Dis 2008; 40: 46-53.

[28] Compstom J. Is fracture risk increased in patients with coeliac disease? Gut 2003; 52: 459-60.

[29] Buchman AL. Population-based screening for celiac disease. Improvement in morbidity and mortality from osteoporosis. Arch Intern Med 2005; 116: 370-2.

[30] Valdimarsson T, Löfman O, Toss G, Ström M. Reversal of osteopenia with diet in adult celiac disease. Gut 1996; 38: 323-7.

[31] Mataulen C, Gonzalez D, Mazure R, et al. Effect of treatment on bone mass, mineral metabolism and body composition in untreated celiac disease patients. Am J Gastroenterol 1997; 92: 313-8.

[32] Kemppainen T, Kröger H, Janatuinen E, et al. Bone recovery after gluten-free diet: a 5-year follow-up study. Bone 1999; 25: 355-60.

[33] Sategna-Guidetti C, Grosso SB, Grosso S, et al.The effects of 1year gluten withdrawal on bone mass, bone metabolism and nutritional status in newly-diagnosed adult celiac disease patients. Aliment Pharmacol Ther 2000; 14: 35-43

[34] NOF's Health Professional Resources new clinician's guide to prevention and treatment of osteoporosis. Washington D.C. 2008. Available from: www.nof.org/ professionals/clinicansguide

[35] Black DM, Delmas P, Eastell R, et al. Once-yearly zolendronic acid for treatment of postmenopausal osteoporosis. N Engl J Med 2007; 356: 1809-22.

Received: December 11, 2008

Revised: January 13, 2009

Accepted: January 14, 2009

(C) Pérez-Castrillón et al.; Licensee Bentham Open.

This is an open access article licensed under the terms of the Creative Commons Attribution Non-Commercial License (http://creativecommons.org/licenses/by$\mathrm{nc} / 3.0 /$ ), which permits unrestricted, non-commercial use, distribution and reproduction in any medium, provided the work is properly cited. 